\title{
Errors in rational expectations matter
}

Citation for published version (APA):

Borghans, L. (1992). Errors in rational expectations matter. Researchcentrum voor Onderwijs en Arbeidsmarkt, Faculteit der Economische Wetenschappen. ROA Research Memoranda No. 4E https://doi.org/10.26481/umaror.199204E

Document status and date:

Published: 01/01/1992

DOI:

10.26481/umaror.199204E

Document Version:

Publisher's PDF, also known as Version of record

\section{Please check the document version of this publication:}

- A submitted manuscript is the version of the article upon submission and before peer-review. There can be important differences between the submitted version and the official published version of record.

People interested in the research are advised to contact the author for the final version of the publication, or visit the DOI to the publisher's website.

- The final author version and the galley proof are versions of the publication after peer review.

- The final published version features the final layout of the paper including the volume, issue and page numbers.

Link to publication

\footnotetext{
General rights rights.

- You may freely distribute the URL identifying the publication in the public portal. please follow below link for the End User Agreement:

www.umlib.nl/taverne-license

Take down policy

If you believe that this document breaches copyright please contact us at:

repository@maastrichtuniversity.nl

providing details and we will investigate your claim.
}

Copyright and moral rights for the publications made accessible in the public portal are retained by the authors and/or other copyright owners and it is a condition of accessing publications that users recognise and abide by the legal requirements associated with these

- Users may download and print one copy of any publication from the public portal for the purpose of private study or research.

- You may not further distribute the material or use it for any profit-making activity or commercial gain

If the publication is distributed under the terms of Article $25 \mathrm{fa}$ of the Dutch Copyright Act, indicated by the "Taverne" license above, 
ERRORS IN RATIONAL EXPECTATIONS MATTER

ROA-RM-1992/4E

Lex Borghans

RESEARCH CENTRE FOR EDUCATION AND THE LABOUR MARKET

Faculty of Economics and Business Administration

Rijksuniversiteit Limburg

Maastricht, August 1992 
CIP-GEGEVENS KONINKLIJKE BIBLIOTHEEK, DEN HAAG

Borghans, Lex

Errors in rational expectations matter / Lex Borghans.- Maastricht: Research Centre for Education and the Labour Market, Faculty of Economics and Business Administration, Rijksuniversiteit Limburg.- (ROA-RM-1992/4E)

Met lit. opg.

ISBN 90-5321-089-X in spiraalband

Trefw.: arbeidsmarkt; toekomst. 
CONTENTS

Page

ABSTRACT

1. INTRODUCTION

2. STATES OF THE WORLD

3. ERRORS IN FORECASTS $\quad 8$

4. PREDICTION ERRORS: INFORMATION VERSUS INTERPRETATION ERRORS 11

5. IMPLICATIONS 16

REFERENCES 


\section{ABSTRACT}

Rational expectations theory is often criticised because of its strong assumption concerning people's capacities to make good forecasts. For situations with non-professional decision makers (in this paper students choosing between different occupations) this assumption is unrealistic. Muth (1961), and Sargent and Wallace (1976) claimed, however, that the main results of rational expectations theory allow for a possibly large independent error in rational expectations. This paper gives a straightforward extension of the rational expectations model which shows that in such a situation the pseudo rational expectation is not optimal anymore. 


\section{INTRODUCTION}

Uncertainty plays an important role in the educational choice of students. The educational choice may determine the occupational possibilities a student will have afterwards, and since many courses take several years, the labour market situation of those occupations will not be known with certainty at the moment the educational decision has to be made. Students therefore have to base their decisions on expectations about the future labour market situation.

Freeman $(1971,1975 a, 1975 b)$ has introduced an enrolment model with uncertainty about the future wage by use of the cobweb expectation theory. This cobweb model has been criticised for its unrealistic character by Siow (1984) and Zarkin (1985). They replaced the cobweb expectation by rational expectations. Rational expectations are of course more satisfying from a theoretical point of view, but in the context of educational choice, they are not unproblematic. The rational expectation theory makes a very strong assumption about people's capabilities to calculate the optimal forecast. All prediction errors made by forecasters are assumed to be due to uncertainty about the future state of the world, while no errors in the forecast itself are made. Therefore, a perfect insight in the functioning of the labour market is required. It is unlikely that students do have such a perfect insight in the very complex labour market. Muth (1961), and Sargent and Wallace (1975) claim, however, that the main results of the rational expectation model are not influenced by the introduction of a (possibly very large) independent random error term. Both papers do, however, not provide a for proof this claim. In the rational expectation model such proof is not possible directly, because the theory does not provide any alternative expectation that can be used by the forecaster.

In this paper, firstly, the states-of-the-world-type of prediction errors (section 2) and the errorin-forecasts (section 3) are discussed. In section 4 a model is introduced which is a straightforward extension of the rational expectations model. Based on this model it is shown that it is not optimal for a student who disposes of the pseudo rational expectation (i.e. the rational expectations plus a random error) to use only this expectation. 


\section{STATES OF THE WORLD}

Suppose students have to forecast the wage they will earn after some kind of schooling to make their enrolment decision. In general their prediction ( $w^{\text {pre }}$ ) will not equal the realisation $\left(w^{\text {rea }}\right)$. Their difference, the prediction error $\Delta \bar{w}=w^{\text {rea }}-w^{\text {pre }}$, can be viewed upon as the realisation of a stochastic variable. The essence of prediction errors is that the person who makes the error does not know its value. Therefore the assumption is made that although the realisation of the prediction error mostly differs from 0 , the expectation of the prediction error, $\boldsymbol{E}\{\Delta \vec{w}\}$, equals 0 . The reason to model the prediction error in this way comes from the fact that, from the viewpoint of the student, it is not possible to correct this error. It does however not explain the source of such prediction errors. There are two basic models of the sources of prediction errors in economics, which are discussed in this and the next section.

In this section the 'states of the world' model is discussed. This model is the most widely used model of prediction errors in economics. Its basic point is that at the moment some decision has to be made, the (future) consequences of it are not known with certainty. There are different states of the world which can not be excluded beforehand. Table 1 gives an example. In this example a student has to make a choice between two schools. At school $A$ he will get some specialised knowledge, while at school $B$ he will get more generally educated. The question the student is faced with is whether the labour market for the specialised knowledge will be good or bad, at the moment he finishes his school. Therefore, two scenario's are distinguished, state 1 in which the market is indeed good and his earnings measured in utility will be 100, while with the more general education he will only get 50 . On the other hand the situation might be bad, as in state 2 , in which case the earnings with school $A$ will fall to 0 while with school $B$ the earnings remain 50 .

Table 1. Consequences of several choices in different states

$\begin{array}{llr}\text { decision } & \text { state } 1 & \text { state } 2\end{array}$

$\begin{array}{lrr}\text { school } A & 100 & 0 \\ \text { school } B & 50 & 50\end{array}$

It is clear that $A$ would be chosen in state 1 and $B$ would be chosen in state 2 . In both states the cost of a wrong decision (based on a false belief) are 50. The problem of this student is, however, that he does not know which state of the world will be the case. To solve this 
decision problem it is assumed that the student has some subjective probabilities about the probabilities of both states to occur. In table 2 such a subjective probabilities are given. Based on this probability distribution it is possible to calculate the expected value (EV) of both alternatives. The expected value of an alternative $j$ is equal to the weighted gains in the possible states of the world.

(1) $E V^{j}=E\left\{U^{j}\right\}=\sum_{k} p_{k}^{j} U_{k}^{j}$

in which $p_{k}$ is the probability of a certain state of the world, and $U_{k}^{j}$ is the gain with choice $j$ in state $k$.

Table 2. A subjective probability distribution

subjective probability

$0.80 \quad 0.20$

school $\boldsymbol{A}$

In this example

$$
\begin{aligned}
& E V^{A}=0.8 * 100+0.2 * 0=80 \\
& E V^{B}=0.8 * 50+0.2 * 50=50
\end{aligned}
$$

The states of the world model asserts that, without further information, the agent will choose the alternative with the maximal expected utility, so he will choose school $A$. More in general, the choice $J \in\{A, B\}$ is such that

(2) $E V^{J}=\operatorname{MAX} E V^{j}$

An interesting question in this model is what are the welfare costs of not having perfect information, or stated inversely, what is the value of perfect information. These costs of uncertainty $(W)$ depend on the contents of the information. For a certain state it can be defined 
as the value without the certain knowledge, minus the value of the optimal decision in that state.

(3) $W_{k}=U_{k}^{J}-\underset{1}{\operatorname{MAX}} U_{k}^{j} \leq 0$

By definition these costs will always be less than or equal to zero.

In the example

$W_{1}=100-100=0$

$W_{2}=0-50=-50$

If the student gets perfect information, which tells him state 1 will be the case, his gain is zero, because his decision will not change due to the extra information. If, however, the perfect information tells him state 2 will be the case his gain is 50 , because now he can anticipate this state by changing his decision from school $A$ to $B$.

The state the information will predict, however, is not known beforehand, so a student has to calculate the expected value of perfect information, which can be calculated by again weighing with the subjective probability distribution.

(4) $W(p)=\boldsymbol{E}\{W\}=\sum_{k} p_{k} W_{k}$

In the example this negative welfare effect due to imperfect information is $0.2 *-50=-10$.

A problem in this theory of uncertainty is that the calculation of the value of information is only correct if the subjective probability distribution is correct. A probability distribution that is correct, i.e. which corresponds to the real probability distribution is called an objective probability distribution.

The assumption of a subjective probability distribution, asserts that students do view the future world as stochastic. They assign, mentally, probability values to the different states of the world they distinguish. The assumption of the existence of an objective probability distribution is much stronger. It states that the real world is not only viewed upon as stochastic, but really is stochastic. Many theories assume, furthermore, that the subjective probabilities will equal the objective probabilities. Students do, in their view, face uncertainty, and they do make errors 
due to this uncertainty, but the real source of these errors is the stochastic character of the world. Keynes (1937) calls this type of uncertainty (mathematical) risk, which he compares to gambling roulette: The probability distribution is known with certainty, but the realisation depends on chance. In rational expectations theory this assumption, that objective probability distribution equals the subjective probability distribution is essential. Furthermore in this theory the objective probability distribution is assumed to be equal to the probability distribution of the model.

Thus, a subjective probability function which assigns a too high probability to the one, and a too low probability to the other state, has two effects. The student will too much emphasise the consequences in the first state (because he has overestimated the probability this will occur), and he will underestimate the value of extra information, because he underestimates the probability that there will be a deviation from his expectations. The subjective probability distribution serves in this context both as a statement about the probability of the two states, and implicitly as a statement about the quality of this information. Students do not realise that their expectations may be incorrect. In a situation in which it is assumed that the subjective probabilities equal the objective probabilities, this is no problem because students are indeed always right by definition. If it is allowed, however, that the subjective probabilities differ from the objective probability, there rises a discrepancy between the complete confidence students have in their (stochastic) forecasts, and the differences between subjective and objective probabilities, which are assumed to exist.

A method to overcome this problem is by use of Bayesian statistics. Suppose that in the example the objective probability distribution is $(0.7,0.3)$, i.e. the economic environment is such that with $70 \%$ chance state 1 will occur, while state 2 has a $30 \%$ probability. Initially, however, this objective probability function is not known to the students. To model this uncertainty the assumption is made that conform Bayesian statistics, for the students the value of $p_{1}$, the probability of state 1 , is itself a stochast. The assumption is therefore made that they assign equal probabilities to every value of $p_{1}$ (see figure 1, (a)). After 1 year the world provides the students with one realisation of the state of the world. This information enables the students to update their prior probabilities according to Bayes' rule:

(5) $P\left(p_{1} \mid\right.$ state $\left._{t}\right)=\frac{P\left(\text { state }_{t} \mid p_{1}\right) \cdot P\left(p_{1}\right)}{\int_{p_{1}} P\left(\text { state }_{t} \mid p_{1}\right) \cdot P\left(p_{1}\right) d F\left(p_{1}\right)}$

Graph (b) in figure 1 gives the prior distribution after one year. In this year the state of the world was 1 and therefore the prior probability of high values of $p_{1}$ has risen. Graph (c) gives 
the prior after 10 years, while (d) gives the situation after 100 years.

Figure 1. The prior distribution of $p_{1}$ after (a) 0 , (b) 1, (c) 10 , and (d) 100 year(s)

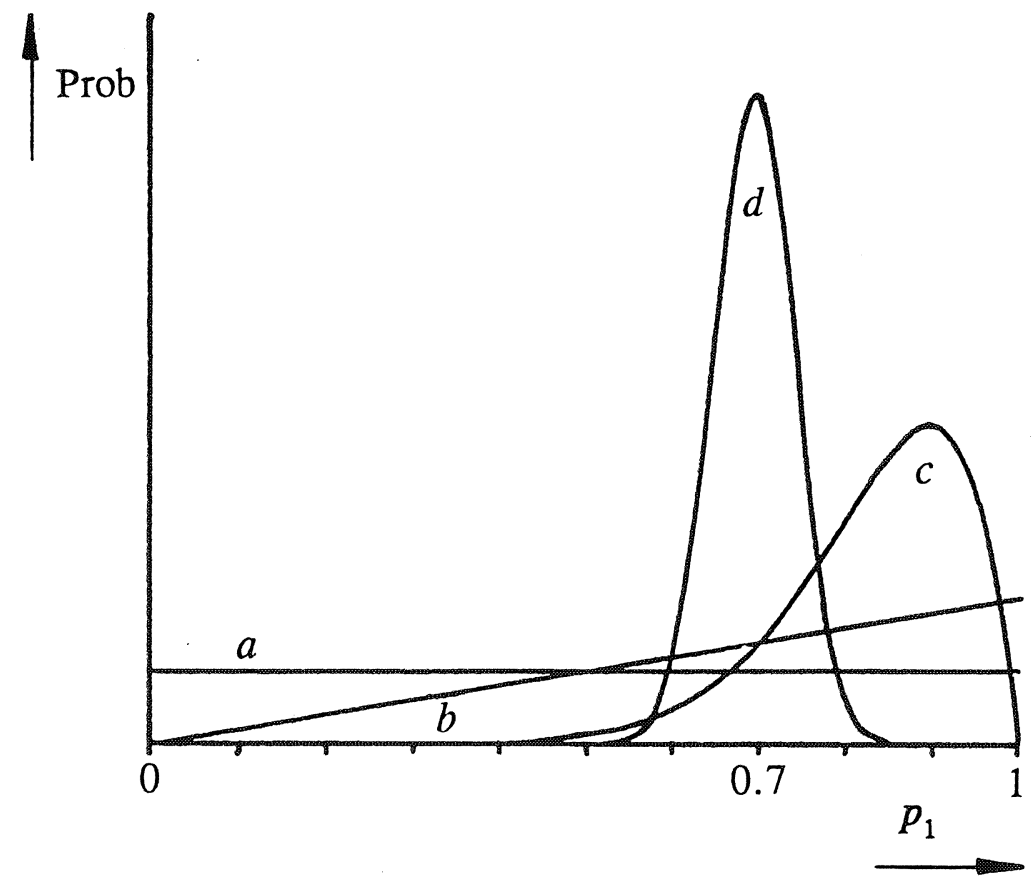

This Bayesian approach to model the uncertainty with respect to the objective probabilities is very disputable. The fundamental problems of the approach are already observed by Knight (1921), Keynes (1937), and Shackle (1949). The main issue is that this model preassumes a clear relation between past events and future probabilities. It is a frequentistic approach. The only information about the probabilities of the states of the world are the realisations in the past. This requires that (i) the situation in the past were evidently completely identical to the future situation, and (ii) there are no other possibilities to say anything about future events than what is enclosed in past events.

Shackle (1949) has stressed that every future event is to some extent unique. Relating such a future event to the past experience is not an undisputable calculus, but is based on a human assessment about the nature of the future event. The forecaster uses experience as an indicator for the future. There is, however, no rule which tells which indicator is the best. Furthermore, there may be other things than data on the past, which may be informative about a future situation. The forecaster may have some argumentation or opinion about the future. This may also influence his forecast, although there does not exist a precise relation between the past 
and this forecast.

In the example used in this section only two states of the world have been distinguished. More general it can be assumed that there is a continuum of states of the world. Of course only those states have to be taken into account which are relevant for the decision that has to be made. If a students' decision only depends on the wage, than all states of the world can be described by the wage that will prevail in that state. The objective probability distribution will be a distribution of those wages. With a MSE loss function decisions based on this probability distribution will only depend on the mean of the distribution, while for a comparison of the quality of the forecast the variance is sufficient. The probability distribution therefore can be summarised by the mean and the variance. 


\section{ERRORS IN FORECASTS}

The states of the world view on expectations formation asserts that people recognise that the future world is stochastic to some extent. Therefore, these people base their decisions on the probability distribution of these future events. If these probabilities are not known to them with certainty, the construction is extended one stage by the introduction of prior probabilities of these objective probability distributions. The difficulty of this approach is, however, that it should be a priori clear to every person how to infer probabilities from past data. In the construction of a probability function, the decision has to be made which past events are similar to the future event, and to what extent. Furthermore, argumentations and theoretical thoughts might be also viewed upon as 'data' for the construction of the probability function.

The problematic character of these decisions becomes most clear in a situation in which no extended set of data about the past exists. Suppose a new study 'environmental sciences' is introduced. A students considers to follow this course. His only concern is the total enrolment. He argues that due to the fact that the study did not exist until now, environmentalists will be scarce, and therefore the prospects at the moment are much better than they will be after four years, at the moment all these students enter the market. On the other hand it might also be possible that the total supply will only be a drop in the ocean, due to the growing demands for this discipline. He might decide to compare his arguments with the experiences of other studies, which started recently. He could use the frequency of oversupply in those cases as an indication of the probability that this will happen again, but then he wonders whether all these situations are comparable. Some studies were started due to growing labour market demand as in the case of environmental science, while others were not.

In the judgement of the probability of oversupply, both theoretical and empirical arguments may be used. The theoretical arguments that will be used differ from person to person and it will in general be impossible to foresee who is going to use which argument. The use of theoretical concepts is not simply a function of some characteristics of the person. The same is, however, true for empirical arguments. Although the data may be public domain, the decision which cases to compare the future situation with, and how to design this comparison is a personal judgement. The data itself does not provide a method which way of inference is the best.

Because expectations depend on personal judgements, expectations will in many cases differ from person to person. Such an interpersonal dispersion will in general be low in professional situations. In such a situation forecasts will be made by people who join a comparable theoretical background, and who will communicate much about the topic. Both aspects will 
make the opinions converge. This does, however, not alter the fact that the forecasts may contain a mistake.

In cases where people make forecast statements which do not include probabilities, but simply foretell something to happen as if it were with certainty, it is clear that forecast errors will be made. These errors are very easy to detect. If the predicted event does not occur the forecast is false. In the case predictions are formulated as probability events, such a evaluation is not so easy. If an event which has been predicted with a high probability, does not occur, the forecast might be wrong, or the less probable event might have happened by chance. Although it is not possible to detect errors with certainty, there is, however, no reason to think that a statement like state 1 is going to happen with probability 0.8 while state 2 will occur with probability 0.2 can not be incorrect.

Subjective probabilities are such a type of incorrect predictions. If the subjective probabilities do not equal the objective probabilities, the forecaster makes an error, although he might probably not recognise his error, since the realisation may be both explained by the objective and the subjective probability function. The extension to the model in which the probabilities are themselves stochastic does not overcome this problem. The probabilities remain subjective, and therefore possible incorrect, as long as the prior distribution and the link between past events and this prior distribution are not known with certainty. The model with stochastic parameters may be very useful to model learning by doing, but it does not solve the problem of possible errors in the forecast.

Thus, although Bayesian analysis may be very useful to model uncertainty, it is not able fully to exclude error of a classical type in which the forecast actually made is only an approximation to the optimal forecast. In the states of the world model the prediction error is the difference between what was most likely to happen $\left(w^{\text {pre }}\right)$, and the realisation $\left(w^{\text {rea }}\right)$. The state of the world might deviate from the prediction:

(6) $w^{\text {rea }}=w^{\text {pre }}+\varepsilon$

The error term $\varepsilon$ is independent of the prediction. In the errors in forecast model, however, people make errors because the forecasts deviate from the optimal forecast, which is in an extreme example equal to the realisation:

(7) $w^{\text {pre }}=w^{\text {rea }}+\varepsilon$ 
In this case the error is independent of the realisation. Of course, both models are extreme variants. It may be the case that both types of error occur in a forecast. In that case there exists an unobserved optimal forecast ( $w^{r e}$, in which re stands for rational expectation) such that:

(8) $\left\{\begin{array}{l}w^{r e a}=w^{r e}+\epsilon_{1} \\ w^{p r e}=w^{r e}+\epsilon_{2}\end{array}\right.$

$\epsilon_{1}$ is independent of $w^{\text {pre }}$, while $\epsilon_{2}$ is independent of $w^{\text {rea }}$.

The possibility of errors in forecasts is also observed by proponents of rational expectations, which is a typical states of the world model. In rational expectations forecast errors are always due to unforecastable exogenous shocks.

Muth (1961, p. 321) however states that it is possible that there will be deviations from rationality. 'certain imperfections and biases in the expectations may also be analyzed with the methods of this paper. Allowing for cross-sectional differences in expectations is a simply matter, because their aggregate effect is negligible as long as the deviation from the rational forecast for an individual firm is not strongly correlated with those of the others.'

Sargent and Wallace (1976, p. 180) remark that 'in this regard, it should be noted that the rational expectations hypothesis does not require that people's expectations equal conditional mathematical expectations, only that they equal conditional mathematical expectations plus what may be a very large random term (random with respect to the conditioning information).'

The unproved proposition of Muth, Sargent and Wallace is that errors in forecasts do not matter. In the next section it will be shown that this proposition is false. The presence of errors in forecasts influences the optimal predictions. 


\section{PREDICTION ERRORS: INFORMATION VERSUS INTERPRETATION ER- RORS}

In section 2 a model is presented in which forecast errors are due to unpredictable events in the future. In section 3 it is argued that it is unlikely that this type of forecast errors is the only type that exists. Although it might be difficult to distinguish, forecasts are likely to be incorrect themselves. In this section a model is developed, in which the two types of errors occur simultaneously and in which a trade off between the two errors is possible.

Suppose again that a student has to make a prediction of the future wage to base his enrolment decision on. There are many different approaches to make such a forecast and there is no reason to choose for one of these methods in advance. One approach is to base the forecast on similar past events. The student has to select cases which appear to him identical to some extent. This selection leads to a subjective probability distribution as described in section 2. A problem is, however, to decide which past events are still seen as similar and which are not. The larger the class of similar cases the less informative the probability distribution will become.

On the other hand it may be possible to restrict the class of similar cases. Such a restriction will be based on theoretical arguments about what is typical for the event which has to be predicted. In the case the future event is thought to be very typical, it may be the case that no similar events can be found in the empirical data. The only comparable events are constructions of the mind. In that case the forecast will be purely theoretical. The more restrictive the selection of comparable events is, the more informative the selection becomes, but also the larger the probability is that a wrong selection is made.

The student has to choose between the information errors of a very large set of comparable events, and the interpretation errors in case of a small set of comparable events. It is therefore not sensible to distinguish only one (unobservable) perfect prediction as in equation (8), but there will be a continuum of perfect predictions, rankable from a low degree of informativity to a high degree of informativity. In this section the analysis is restricted to two different unobservable perfect predictions, but this can easily be extended to more.

Let $w_{1}^{\text {re }}$ be a perfect expectation with a high degree of abstraction, and therefore a low degree of informativity, and let $w_{2}^{r e}$ be a more specific perfect expectation. Equation (8) can be extended to: 
(9) $w^{r e a}=w_{2}^{r e}+\varepsilon_{2}^{r e}$

(10) $w_{2}^{r e}=w_{1}^{r e}+\varepsilon_{1}^{r e}$

(11) $w_{2}^{\text {exp }}=w_{2}^{r e}+\varepsilon_{1}^{\text {exp }}+\varepsilon_{2}^{\text {exp }}$

(12) $w_{1}^{\text {exp }}=w_{1}^{\text {re }}+\varepsilon_{1}^{\text {exp }}$

In which the error-terms are always independent of the other right-hand-side variables. $w_{1}^{r e}$ is an abstract perfect prediction of the realised wage, but can also be seen as a perfect prediction of the more specific perfect prediction $w_{2}^{r e}$. Both perfect predictions are only observed with an additional measurement error. The assumption is made that the observation of the specific perfect prediction $w_{2}^{r e}$ contains at least the error of the abstract perfect prediction $w_{1}^{r e}$.

In a rational expectations model the measurement errors $\varepsilon_{i}^{\text {exp }}$ equal 0 . In that case the specific model dominates the abstract model, so it is optimal to use the most specific model. The proposition of Muth, Sargent and Wallace, however, is that this is still the case if measurement errors are introduced to the model. It is however easy to show that it is possible in that case to gain from a combination, $w^{\text {pre }}$, of both expectations:

$$
\begin{aligned}
w^{\text {pre }}= & \lambda w_{1}^{\text {exp }}+(1-\lambda) w_{2}^{\text {exp }} \\
= & \lambda\left(w_{1}^{r e}+\varepsilon_{1}^{\text {exp }}\right)+(1-\lambda)\left(w_{2}^{r e}+\varepsilon_{1}^{\text {exp }}+\varepsilon_{2}^{\text {exp }}\right) \\
= & \lambda\left(w^{r e a}-\varepsilon_{1}^{r e}-\varepsilon_{2}^{r e}+\varepsilon_{1}^{\text {exp }}\right) \\
& +(1-\lambda)\left(w^{r e a}-\varepsilon_{2}^{r e}+\varepsilon_{1}^{\text {exp }}+\varepsilon_{2}^{\text {exp }}\right)
\end{aligned}
$$

The prediction error of this combined prediction is:

$$
\text { (14) } \begin{aligned}
\Delta \bar{w} & =w^{\text {pre }}-w^{r e a} \\
& =\lambda\left(\varepsilon_{1}^{\text {exp }}-\varepsilon_{1}^{r e}-\varepsilon_{2}^{r e}\right)+(1-\lambda)\left(\varepsilon_{1}^{\text {exp }}+\varepsilon_{2}^{\text {exp }}-\varepsilon_{2}^{r e}\right) \\
& =\lambda\left(-e^{r e}\right)+(1-\lambda) \varepsilon_{2}^{\text {exp }}+\varepsilon_{1}^{\text {exp }}-\varepsilon_{2}^{r e}
\end{aligned}
$$

The combination is optimal for the value of $\lambda$ for which the variance is minimal. Denoting the variances of the errors with respectively $\sigma_{r e 1}^{2}, \sigma_{r e 2}^{2}, \sigma_{\text {expl } 1}^{2}$, and $\sigma_{\text {exp } 2}^{2}$ the variance of the prediction error equals: 
(15) $\sigma_{w}^{2}=\lambda^{2} \operatorname{VAR}\left\{\varepsilon_{1}^{\exp }-\varepsilon_{1}^{r e}-\varepsilon_{2}^{r e}\right\}+(1-\lambda)^{2} \operatorname{VAR}\left\{\varepsilon_{1}^{\exp }+\epsilon_{2}^{\exp }-\epsilon_{2}^{r e}\right\}$

$$
\begin{aligned}
& -2 \lambda(1-\lambda) \operatorname{CoV}\left\{\varepsilon_{1}^{\exp }-\varepsilon_{1}^{r e}-\varepsilon_{2}^{r e}, \varepsilon_{1}^{\exp }+\varepsilon_{2}^{\exp }-\varepsilon_{2}^{r e}\right\} \\
= & \lambda^{2}\left(\sigma_{\exp 1}^{2}+\sigma_{r e 1}^{2}+\sigma_{r e 2}^{2}\right)+(1-\lambda)^{2}\left(\sigma_{\text {exp } 1}^{2}+\sigma_{\text {exp } 2}^{2}+\sigma_{r e 2}^{2}\right) \\
= & \lambda^{2} \sigma_{r e 1}^{2}+(1-\lambda)^{2} \sigma_{\exp 2}^{2}+\sigma_{\exp 1}^{2}+\sigma_{r e 2}^{2}
\end{aligned}
$$

Minimising equation (15) with respect to $\lambda$ gives:

$$
\text { (16) } \begin{aligned}
\frac{d \sigma_{w}^{2}}{d \lambda}= & 2 \lambda\left(\sigma_{\text {exp } 1}^{2}+\sigma_{r e 1}^{2}+\sigma_{r e 2}^{2}\right)-2(1-\lambda)\left(\sigma_{\text {exp } 1}^{2}+\sigma_{\text {exp } 2}^{2}+\sigma_{r e 2}^{2}\right) \\
& -2\left(\sigma_{e x p 1}^{2}+\sigma_{r e 2}^{2}\right)+4 \lambda\left(\sigma_{\text {exp } 1}^{2}+\sigma_{r e 2}^{2}\right) \\
= & 2 \lambda \sigma_{r e 1}^{2}-2(1-\lambda) \sigma_{\text {exp } 2}^{2}=0
\end{aligned}
$$

Thus, the combination is optimal for

(17) $\lambda=\frac{\sigma_{\exp 2}^{2}}{\sigma_{r e 1}^{2}+\sigma_{e x p 2}^{2}}$

This result shows that only the additional expectation errors are relevant for the choice. $\sigma_{\text {exp } 2}^{2}$ is the error of the specific expectation compared to the abstract expectation. By introducing the specific expectation an additional interpretation error appears. $\sigma_{r e l}^{2}$ is the additional information error of the abstract expectation, compared to the specific expectation.

The most specific expectation is optimal only if $\sigma_{\text {exp2 }}=0$ or $\sigma_{\text {rel }}^{2}=\infty$. The proposition of Muth, Sargent, and Wallace is therefore not true in this construction. The only exception is the case in which only one expectation exists, or $\sigma_{r e l}^{2}=\infty$, i.e. the more abstract expectation is completely uninformative. 
Figure 2. A Bayesian interpretation of the combination of abstract and specific forecasts

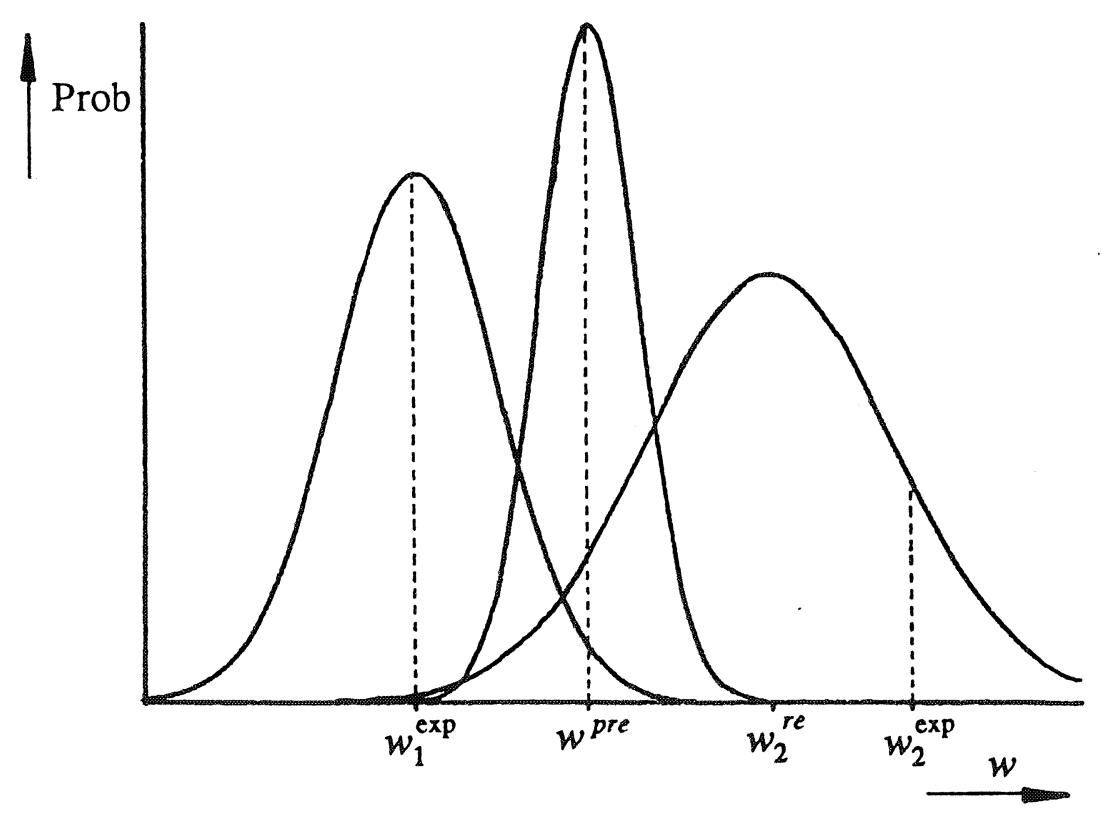

The result (17) can be given an Bayesian interpretation (see figure 2). $w_{1}^{\text {exp }}$, with $\sigma_{\text {rel }}^{2}$ can be seen as a prior distribution for the realised wage. The optimal prediction is the posterior distribution after inference with $w_{2}^{\exp }$. The variance of this posterior distribution, i.e. the variance of $w^{\text {pre }}$ equals:

$$
\begin{aligned}
\sigma_{p r e}^{2} & =\lambda^{2} \sigma_{r e 1}^{2}+(1-\lambda)^{2} \sigma_{e x p 2}^{2} & +\sigma_{e x p 1}^{2}+\sigma_{r e 2}^{2} \\
& =\lambda \sigma_{r e 1}^{2} & +\sigma_{e x p 1}^{2}+\sigma_{r e 2}^{2} \\
& =(1-\lambda) \sigma_{e x p 2}^{2} & +\sigma_{e x p 1}^{2}+\sigma_{r e 2}^{2}
\end{aligned}
$$

This Bayesian interpretation of expectation formation differs, however, strongly from the model presented in section 6.2. In the usual model the prior distribution is based on some a priori theoretical insight in the possible distribution of the parameters, while empirical events provide the model with data for inference. In the model of this section the prior distribution is formed by the frequency of past events, while theoretical insights are viewed upon as data from a distribution centred round the real value of wage which has to be forecasted. 
While in the usual model forecasts improve from new data, the main improvements in this model come from additional theoretical insights. New data, however, may also improve the forecast, because it will improve the prior distribution, which is not without error in the model of this section. 


\section{IMPLICATIONS}

The model provided in section 4 shows that if students are expected to deviate from the rational expectation by independent random errors, it becomes optimal for them to deviate from this pseudo rational expectation and to make some systematic errors in their forecasts. This result has two important implications.

Firstly, such systematic deviations from the rational expectation make it possible for to use policies which manipulate people's expectations. In Borghans (1992) it is shown, however, that the possibilities of such expectations manipulation policies, in this model, are restricted.

Secondly, the recognition of errors in forecasts by the students makes it possible to model an economic policy which aims at the improvement of students' expectations, by the provision of public labour market information as described in Borghans, De Grip, and Heijke (1990). Such a provision of public labour market information can be interpreted as a decrease of errors in the forecasts made by students $\left(\sigma_{\text {exp } 2}^{2}\right)$. This improvement of students' expectations may improve the match between education and labour market. 


\section{REFERENCES}

Borghans, L. (1992), 'Policy Implications of a Rejection of the Rational expectations Hypothesis'. ROA-Research Memorandum, Maastricht.

Borghans, L., A. De Grip, and H. Heijke (1990), 'Labour Market Information and the Choice of Vocational Specialisation'. ROA-Working Paper-1990/2E, Maastricht.

Freeman, R.B. (1971), The Market for College-trained Manpower; A Study in the Economics of Career Choice. Cambridge (Mass.), Harvard University Press.

Freeman, R.B. (1975a), 'Legal "Cobwebs": a Recursive Model of the Market for New Lawyers'. Review of Economics and Statistics, pp. 171-179.

Freeman, R.B. (1975b), 'Supply and salary Adjustments to the Changing Science Manpower Market: Physics, 1948-1973'. The American Economic Review 65-1, pp. 27-39.

Keynes, J.M. (1937), 'The General Theory of Employment'. The Quarterly Journal of Economics, pp. 209-223.

Knight, F. (1921), Risk, Uncertainty, and Profit. New York, Houghton Mifflin.

Muth, J.F. (1961), 'Rational Expectations and the Theory of Price Movements'. Econometrica 29, pp. 299-306.

Sargent, T.J., and N. Wallace (1976), 'Rational Expectations and the Theory of Economic Policy'. Journal of Monetary Economics 2, pp. 169-183.

Siow, A. (1984), 'Occupational Choice under Uncertainty'. Econometrica 52, pp. 631-645.

Shackle, G.L.S. (1949), 'Probability and Uncertainty'. Metronomica, pp. 161-173.

Zarkin, G.A. (1985), 'Occupational Choice: An Application to the Market for Public School Teachers'. The Quarterly Journal of Economics 100, pp. 409-446. 
the prior after 10 years, while (d) gives the situation after 100 years.

Figure 1. The prior distribution of $\boldsymbol{p}_{1}$ after (a) 0 , (b) 1 , (c) 10 , and (d) 100 year(s)

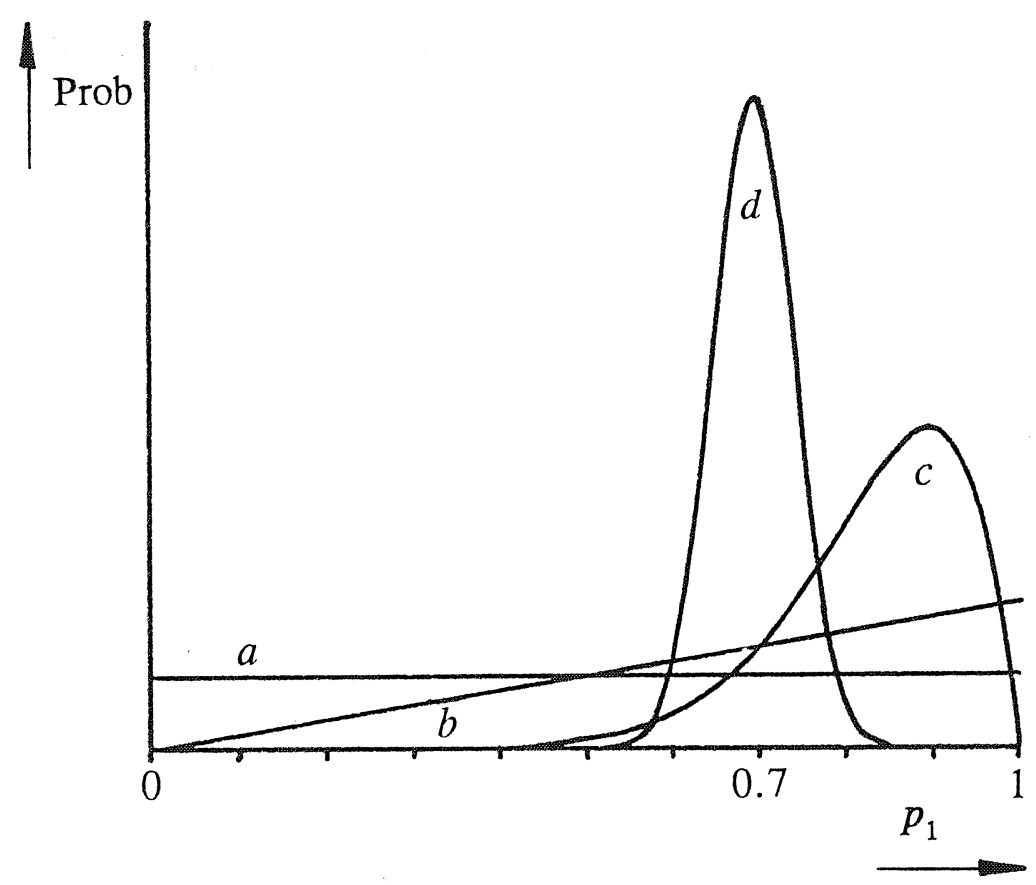

This Bayesian approach to model the uncertainty with respect to the objective probabilities is very disputable. The fundamental problems of the approach are already observed by Knight (1921), Keynes (1937), and Shackle (1949). The main issue is that this model preassumes a clear relation between past events and future probabilities. It is a frequentistic approach. The only information about the probabilities of the states of the world are the realisations in the past. This requires that (i) the situation in the past were evidently completely identical to the future situation, and (ii) there are no other possibilities to say anything about future events than what is enclosed in past events.

Shackle (1949) has stressed that every future event is to some extent unique. Relating such a future event to the past experience is not an undisputable calculus, but is based on a human assessment about the nature of the future event. The forecaster uses experience as an indicator for the future. There is, however, no rule which tells which indicator is the best. Furthermore, there may be other things than data on the past, which may be informative about a future situation. The forecaster may have some argumentation or opinion about the future. This may also influence his forecast, although there does not exist a precise relation between the past 
Figure 2. A Bayesian interpretation of the combination of abstract and specific forecasts

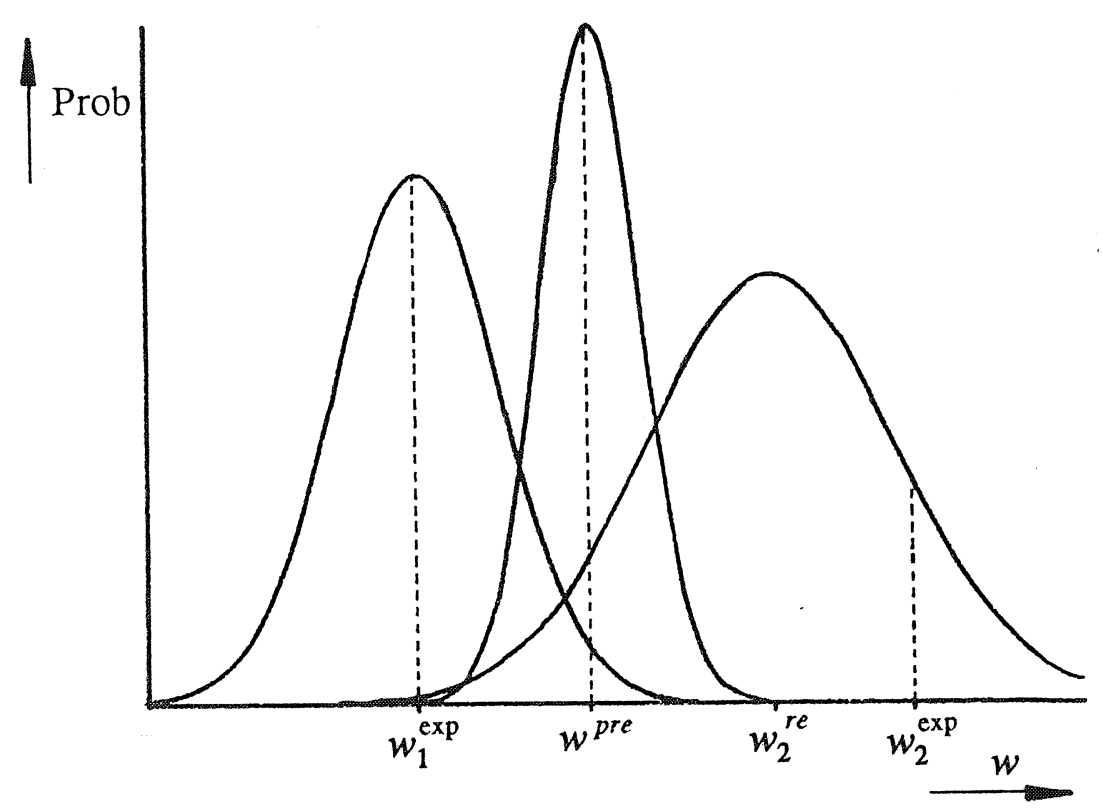

The result (17) can be given an Bayesian interpretation (see figure 2). $w_{1}^{\exp }$, with $\sigma_{r e 1}^{2}$ can be seen as a prior distribution for the realised wage. The optimal prediction is the posterior distribution after inference with $w_{2}^{\exp }$. The variance of this posterior distribution, i.e. the variance of $w^{\text {pre }}$ equals:

(18) $\quad \sigma_{p r e}^{2}=\lambda^{2} \sigma_{r e 1}^{2}+(1-\lambda)^{2} \sigma_{e x p 2}^{2}+\sigma_{e x p 1}^{2}+\sigma_{r e 2}^{2}$

$$
\begin{array}{ll}
=\lambda \sigma_{r e 1}^{2} & +\sigma_{\exp 1}^{2}+\sigma_{r e 2}^{2} \\
=(1-\lambda) \sigma_{\text {exp } 2}^{2} & +\sigma_{\exp 1}^{2}+\sigma_{r e 2}^{2}
\end{array}
$$

This Bayesian interpretation of expectation formation differs, however, strongly from the model presented in section 6.2. In the usual model the prior distribution is based on some a priori theoretical insight in the possible distribution of the parameters, while empirical events provide the model with data for inference. In the model of this section the prior distribution is formed by the frequency of past events, while theoretical insights are viewed upon as data from a distribution centred round the real value of wage which has to be forecasted. 